\title{
High-Impact Practices: The Call for a Commitment to Quality Educational Experiences and Inclusive Excellence
}

\author{
Jennifer Thorington Springer
}

Julie Hatcher

Amy Powell

2018

Without question, existing scholarship and individual practitioner reports all point to the value of highimpact practices (HIPs). HIPs have been encouraged and advocated as effective strategies for promoting engaged learning while simultaneously increasing rates of retention. HIPs such as research, internships, service learning, and collaborative projects are correlated with higher levels of college persistence/completion and with higher levels of learning on twenty-first-century skills. The message regarding the effectiveness of HIPs has been sent and the charge to increase the creation of and student participation in HIPs has been well received by university constituents. Institutional leaders, policymakers, and administrators are advocating for and supporting HIPs. Those who champion the work are reporting successful student outcomes by way of improvements in retention, GPA, deep learning, personal development, practical competence, and gains in broad general educational skills (Brownell and Swaner 2010). More opportunities are being created to afford students participation in multiple highimpact projects that prepare them to integrate and apply their learning to complex questions and problems (Kuh 2015). We know what HIPs are and why they matter. We know that they are valuable. So, what's next? What's trending? We have moved beyond the value of HIPs; we ask what tools/mechanisms are in place to assess the quality of HIPs? To what extent are HIPs available to all students? Are underserved

This is the author's manuscript of the article published in final edited form as:

Springer, J. T., Hatcher, J., \& Powell, A. (2018). High-Impact Practices: The Call for a Commitment to Quality Educational Experiences and Inclusive Excellence. Assessment Update, 30(4), 6-11. https://doi.org/10.1002/au.30141 
students being accounted for in the roll call for participation? Are we being intentional about extending the advantages of HIPs to all students? Is diversity being addressed and are inequities being challenged? What is being done to ensure inclusive excellence? To help answer some of these questions, the plenary and concurrent sessions for the 2017 Assessment Institute HIPs track illuminated and set the stage for engaging conversations regarding the themes at the core of the questions outlined above: attention to quality, diversity, equity, and inclusive excellence in HIPs while ensuring equal access to all students with attention to underserved students.

\section{On Diversity, Equity, and Inclusive Excellence}

Tia McNair's plenary, “Becoming a Student-Ready College: High-Impact Practices and Intentionality by Design," offered an all-encompassing examination of how we might "accelerate broad-scale innovation to advance educational practices that engage diversity and challenge inequities in student outcomes to make excellence inclusive." As institutions work toward addressing how to construct or restructure our educational environment to better accommodate the changing multidimensional needs of incoming students, how might they increase student participation in HIPs and "raise student awareness of the value of guided learning pathways that will promote quality and competition?” McNair's plenary focused on how to develop "institutional models for assessment that promote continuous improvement for HIPs and identify the inconvenient truths about campus environments that may be barriers to student success and higher learning gains." Emphasis was placed on the importance of ensuring that the institution's values align well with strategies for engaging the whole community on becoming student-ready. The question of to what extent HIPs are available to all students is critical. Moreover, the fact that underserved students stand to benefit the most from HIPs but are the least likely to participate must be given due attention (Finley and McNair 2013). What are the existing gaps on your campus in terms of who has access to HIPs, and how can you diversify the demographics? First, there must be attempts made to determine what diverse excellence means on respective campuses and how equity and quality learning can be combined. Explicit equity goals are a must. Institutions should have specific equity goals for undeserved students. 
Culturally inclusive practices and interventions are integral to ensuring that your campus is student-ready. Additionally, McNair raised the question of how your campus gathers evidence of student learning. How do you use that data to talk about what is happening in the classroom? How do you get students to develop as intentional learners? HIPs are what drive student and learning productivity. As we collect the data on who is participating in HIPs, who has access, who needs to be encouraged to participate (such as underserved students), the data must be disaggregated. To date, only $3 \%$ of institutions disaggregate data on achievement of participation in HIPs by race, ethnicity, and/or a parent's education, while $17 \%$ of institutions disaggregate data on achievement of learning outcomes by race, ethnicity, and/or a parent's education. Disaggregating the data can assist with setting and attaining equity goals. References were made to the VALUE (Valid Assessment of Learning in Undergraduate Education) Institute to be launched by the AAC\&U as well as "On Solid Ground," which can be found at http://aacu.org/value. The VALUE Institute is a partnership between AAC\&U and Indiana University's Center for Postsecondary Research. "On Solid Ground" shares the results from the first two years of data collection for the VALUE initiative.

\section{On Quality}

Presenters reported on various types of intentional assessment to assure the quality of HIPs. IUPUI's Amy Powell and Nancy Goldfarb's "Faculty Fellowship to Support Implementation of an HIP Taxonomy" showcased one of the campus's newly created taxonomies for themed learning communities (TLCs). The taxonomies were created as frameworks to guide HIP implementation, instructional strategies, and course design. The TLC taxonomy, like the others, ensures that HIPs are done well when scaled and create the optimal learning experience for all students. Furthermore, they assist in identifying faculty needs. Powell and Goldfarb shared the experiences of those who piloted the taxonomy, the process, case studies, and how a taxonomy may support growth of a HIP program. All IUPUI taxonomies may be found at https://rise.iupui.edu/taxonomies.

Heather M. Pleasants, Mary Anne Connors, and Frannie James from the University of Alabama discussed how their campus instituted an experiential learning program and assessment with a focus on the best 
practices of intentionality, preparedness, monitoring and feedback, reflection, assessment, and evaluation. A Learning In Action Fellows Program was created where faculty would write learning outcomes using the backward design process to create and implement their course, and then present their work to faculty peers for review. The campus measured experiential outcomes: (1) defines problems with situational awareness, (2) identifies and derives solutions, (3) uses academic knowledge in real-world contexts, (4) analyzes and evaluates solutions, and (5) connects academics to real-world contexts. Additional information may be found at https://learninginactionblog.ua.edu.

Support for faculty development through grant funding allows an opportunity for champions of HIPs to assess ongoing programs while making necessary changes to meet student needs. The value of HIPs can be improved through structured assessment, as is the case in the work done by David Sabol, Heather Bowman, and Jan DeWester from IUPUI. They shared how they used mini-grants to conduct a study that reviewed and reshaped the Summer Bridge Program, which began in 2001. The curriculum was reviewed in an effort to assist a growing and diverse faculty on how to best serve a new generation of entering students.

The lines of inquiry and trends within national dialogues about HIPs will no doubt continue to engage questions surrounding the equitable implementation of them, who has access, where the gaps lie, and possible solutions. Institutions will continue to grapple with and seek ways to be that university whose values and commitment to HIPs are aligned with their strategic planning. Practitioners and champions of HIPs will continue to create viable assessment tools to ensure the quality of HIPs. There will be a continued focus on securing a holistic model of assessment regarding student outcomes rather than getting hung up on using HIPs to aid in student retention. Quality is important. McNair sums it up best when she states, "Completion without quality is an empty promise of student success."

NOTE: Assessment Institute Insights is a column featuring ideas, content, and resources from the Assessment Institute in Indianapolis. Now the nation's oldest and largest event focused exclusively on outcomes assessment in higher education, the Assessment Institute attracts some 1,000 participants from 
nearly all 50 states and several foreign countries. The institute features special tracks in assessment related to community engagement, ePortfolios, faculty development, global learning, graduate/graduate professional education, high-impact practices, learning improvement and innovation, NILOA, STEM education, and student affairs programs and services. This year's institute will be held October 21-23, 2018, at the Indianapolis Marriott Downtown. More information about the Assessment Institute may be found at http://assessmentinstitute.iupui.edu/. 


\section{References}

Brownell, J. E., and L. E. Swaner. 2010. Five high-impact practices: Research on learning outcomes, completion and quality. Washington, D.C.: Association of American Colleges and Universities.

Finley, A. and T. McNair. 2013. Assessing underserved students' engagement in high-impact practices, Washington, D.C.: Association of American Colleges and Universities. Retrieved from: http://www.aacu.org/assessinghips

Kuh, G. D. 2015. "High Impact Practices: Retrospective and Prospective.” In Five high impact practices: Research on learning outcomes, completion and quality. page 14 (13-23) Washington, D.C.: Association of American Colleges and Universities. 